\title{
Cómo hablar de Dios desde Ayacucho
}

\section{Gustavo Gutiérrez, Lima, Perú.}

Deseo en primer lugar agradecer la invitación a participar en esta semana organizada por la prestigiosa Universidad de Madrid. ${ }^{1}$ El tema de ella es central para un creyente, pero es igualmente importante para toda persona comprometida con la reflexión sobre el ser humano en el mundo contemporáneo.

Un percance de úlima hora me impide estar fisicamente con ustedes. Debido a ello pierdo la ocasión de enriquecerme con el contacto personal y con el dí́logo directo sobre nuestras respectivas preocupaciones. Tener esa oportunidad fue la razón primera por la que acepté la invitación que amablemente me hizo mi amigo, el profesor Oleganio González de Cardedal. Llevo tal vez demasiado tiempo respirando el aire de esta vieja y húmeda ciudad de Lima para no tener problemas con mis vias respiratorias...

Dios mío, ¿dónde estás?

Dos escritores indígenas del Perú nos ayudarán a dar carne -herida - a la cuestión de Dios, tal como se presenta entre nosotros.

Felipe Guamán Poma de Ayala, nacido a mediados del siglo XVI, en un largo informe destinado al rey Felipe III - escrito en un castellano titubeante y preflado de sintaxis quechua - cuenta que impresionado por la situación de sus hermanos de raza salió a recorrer el antiguo Tahuantinsuyo "en busca de los pobres de Jesucristo." Durante afios "anduvo en todo el mundo para ver y proveer su justicia y remedio de los pobres." Una situación en la que "se desuella y se sirve de los pobres de Jesucristo," le hace exclamar "y así Dios mío, Ladónde estás? No me oyes para el remedio de us pobres, que yo harto remediado ando."

En Guamán Poma la protesta viene de su pertenencia a ese pueblo maltratado, pero también de la nueva fe que ese mismo pueblo ha comenzado a adoptar. Otro testigo, siglos más tarde, nos hace ver que ese sufrimiento se ha hecho cada vez más hondo, impregnando toda la vida de los indios. En la catedral del Cuzco se 
venera una imagen de Cristo cuyo rostro parece reflejar el profundo dolar que se lee en las caras de los indígenas y que por ello - se queja Arguedas - hace sufrir. "el rostro del Crucificado era casi negro, desencajado, como el del pongo (...) Renegrido, padeciendo, el Seffor tenla in silencio que no apacigusba, hacla sufrir. en la catedral tan vasta, entre las llamas de las velas y el resplandor del día que llegaba tan atenuado, el rostro del Cristo creaba sufrimiento, bo extendfa a las paredes, a las bóvedas y columnas. Yo esperaba que de ellas brotaran lágrimas" (Rlos profundos).

Desde el sufrimiento injusto de los indígenas surge la pregunta: ¿dónde está el Dios amor? Esa sigue siendo la fuente del planteamiento sobre Dios en nuestras tierras. Así de simple y de doloroso. Esta posición del problema puede parecer quizá pre-crítica a una mentalidad europea. No es el momento de discutir este punto, ni de interrogarnos acerca del carácter axiomático con que es presentada muchas veces esta perspectiva que viene de la ilustración. Quisiera solo decir que, si la teología es una inteligencia de la fe al servicio del anuncio del evangelio, no podemos esquivar la forma como la gran mayoría de nuestro pueblo vive hoy su relación con el Dios de su fe. Esa práctica creyente es el punto de partida para encontrar nuestro lenguaje sobre Dios.

La indiferencia de quienes se dicen cristianos frente a las condiciones de vida de los pobres, los intentos de justificarlas con razones religiosas y con posteriores compensaciones, o el pedido de resignación a ellas en nombre de la voluntad de Dios, no hacen sino exacerbar el asunto. "¿Quién es Dios? ¿Quién es?," preguntará la indígena jorobada (la kurku) a partir de su sufrimiento e insignificancia en la novela de Arguedas, Todas las sangres. A la interrogante "¿Cree usted en Dios?" lanzada a boca de jarro al personaje central de esta obra, el indigena Rendon Wilka, éste responde con otra interrogante "¿cual Dios sera?" No es una evasión, es una precisión. Más abajo, conforme continúa la discusión, al ver la forma como los hacendados explotadores usan el nombre de Jesucristo, al que su interlocutor se refiere como aquel "que amaba a los pobres y murio en la cruz por ellos," Wilka volverá a preguntar con su estilo propio y casi con irrilación "¿Cuánto Jesucristo hay?" Sólo así se podrá dialogar sobre un terreno sin equívocos ni engafios.

Arguedas se hace eco del sentir de los pobres. "El Dios de los sentores no es igual. Hace sufrir sin consuelo," afirmará el sacristán mestizo en diálogo con un sacerdote que parece creer en un Dios lejano a la vida diaria de los seres humanos. En este Dios se apoyan los poderosos. "Dios me ayuda, para eso existe," dice con arrogancia Don Fermín, rico propietario, otro personaje de la misma novela; y dentro de la misma lógica sostendrá que "el indio ha nacido para sufrir, que Dios asi ha mandado." "Tu Dios, joven Hidalgo — dice agresivamente Wilka en otro diálogo- ¿cómo es? Dios de hacendados, de ingenieros, come gente (...) Contra de Dios. Contra de Dios, diciendo, tranquilos matan gente."

Ante tanto sufrimiento y acicateada por la pretendida justificación religiosa de 
la injusticia, retoma incisiva la pregunta ¿dónde está Dios? En el diálogo a que ya hemos aludido el viejo sacristán responde:

- Dios hay aquí, en Lahuaymarca De San Pedro se ha ido, creo para siempre.

- Tú tampoco eres cristiano verdadero, hijo - replica el cura- ¡ ¡Tantos afios de sacristán! Y piensas como brujo. Dios está en todas partes, en todas partes...

- El viejo sacristán de San Pedro movía negativamente la cabeza.

- ¿Habia Dios en el pecho de los que rompieron el cuerpo del inocente maestro Bellido? ¿Dios está en el cuerpo de los inginieros que están matando "La Esmeralda"? ¿De seffor autoridad que quitó a sus dueflos ese maizal donde jugaba la Virgen con su Hijito, cada cosecha? No me hagas llorar, padrecito. Yo también como muerto ando. Don Demetrio tiene Dios, en la Kurku está Dios, cantando; en don Bruno pelea Dios con el demonio; para mí no hay consuelo, de nadies.

Desde el infortunio el autor del Salmo 42 se preguntaba, angustiado, to mismo. El salmista se interroga con ansiedad sobre la causa de la ausencia de Dios, es decir, acerca del hecho que el Seffor parezca haberse olvidado de él y de su pueblo. Pero no es una cuestión que surja sólo desde la penuria y la angustia; ella es también una expresión de fe. No formularla manifiesta indiferencia u olvido de Dios, aś como un rechazo al poder interpelador de su Palabra (cfr. Jer 2,8).

Nuestro sacristán reencuentra, desde su experiencia, la perspectiva bíblica sobre Dios. Dios no está en los lugares (cfr. Jer 7, 1-7; Mc 11, 15-17), en las personas (cfr. Miq 3, 9-12; Mt 23, 16-17) y en las acciones (cfr. Am 5, 21-24; Is 58, 5-7; Mt 7, 21-23) en las que el amor gratuito de Dios y su exigencia de justicia están ausentes. La presencia de Dios se da allí donde su reino comienza a establecerse. El Dios de Jesús es el Dios dei reino.

Si separamos a Dios de su propósito no creemos realmente en El, porque eso significa recusar su reinado, su voluntad de vida, amor y justicia en la historia. El poeta popular francés Jacques Prevert ponía en labios descreídos una oración que es tal vez la que muchos cristianos rezan en la práctica: "Padre nuestro que estás en los cielos, quédate ahí..." Es decir, "no entres en nuestra historia, déjanos hacer en ella nuestra voluntad y no la tuya." Otro es el comportamiento de Jesús que afirma reiteradamente, en el evangelio de Juan por ejemplo, que él se nutre de la voluntad del Padre. Vale decir que su alimento es el designio del Padre de reinar, su designio de vida, su reino.

El Dios de la Biblia es inseparable de su proyecto, de su reino. En consecuencia todo intento de encontrarlo y comprenderlo divorciándolo de su reinado es, en términos bíblicos, fabricar un ídolo, forjarse un dios a nuestra imagen y deseos, caer en la idolatría, confiar en alguien que no es Dios. En efecto, un dios sin reiro es un fetiche, obra de nuestras manos, negación del Seftor, porque esta 
separación es contraria a sus deseos. El Dios de Jesucristo es el Dios del reino, es Aquel que tiene una palabra y una intención sobre la historia humana Jesús va más lejos todavia Ante la pregunta sobre el momento de la llegada del reino responde: "el reino de Dios ya está entre ustedes" (Lc 17, 21). Jesús el Mesías es el reino.

Hablar del reino es referirse a la gratuidad del amor de Dios y a su exigencia de justicia. Son los dos aspectos que nos hacen comprender que los pobres - los pobres reales, los insignificantes de la sociedad - son los privilegiados del reino. Gratuidad y justicia constituyen las razones de una preferencia que no está en los méritos éticos o en las disposiciones religiosas de los pobres, sino en la bondad de Dios.

Esto también lo intuyó Guamán Poma que en un texto polémico y de honda raíz evangélica afirma:

Que para ello me hice pobre, metiéndome en los demás pobres, que así convenía para este efecto, de como se sabe que al pobre menosprecian los ricos y los soberbios sobre ellos, pareciéndoles que donde está el pobre no está ahí Dios y la justicia. Pues ha de saberse claramente con la fe que donde está el pobre está el mismo Jesucristo; donde está Dios está la justicia.

En el pobre encontramos a Jesús, el reino en medio de nosotros. Es decir en el despojado, en el oprimido, resultado de un sistema social injusto. En aquel que vive en una situación marcada por la muerte hallamos al Seflor de la vida. La perspectiva evangelica nos impide evadimos de la historia, en ella entramos en relación con el Dios que "puso su tienda en medio de nosotros."

En esa historia, la pobreza es hoy un hecho mayor y cruel. La pobreza significa, en última instancia, muerte. Carencia de alimento y de techo, imposibilidad de atender debidamente a necesidades de salud y educación, explotación del trabajo, desempleo permanente, falta de respeto a la dignidad humana e injustas limitaciones a la libertad personal en los campos de la expresión, lo político y lo religioso.

¿De qué manera hablar de un Dios que se revela como amor en una realidad marcada por la pobreza y la opresión? ¿Cómo anunciar el Dios de la vida a personas que sufren una muerte prematura e injusta? ¿Cómo reconocer el don gratuito de su amor y de su justicia desde el sufrimiento del inocente? ¿Con qué lenguaje decir a los que no son considerados personas que son hijas e hijos de Dios? Estas son las interrogantes fontales de la teologia que surge en América Latina, y sin duda también en otros lugares del mundo donde se viven situaciones semejantes.

Con gran sensibilidad J. B. Metz se preguntaba hace unos afios cómo hablar de Dios después de la horrenda experiencia de Auschwilz. Desde eslas tierras, en las que hace siglos ya Bartolomé de Las Casas dejaba a Cristo mil veces flagelado en los indios, nuestra pregunta es Łcómo hablar de Dios, no después sino durante 
Ayacucho?2 La interrogación supera sin duda nuestra capacidad de respuesta Pero sabemos que debemos decir como Job: "no frenaré mi lengua, hablará mi espíritu angustiado, se quejará mi alma entristecida" $(7,11)$.

\section{El Señor, amigo de la vida}

La Biblia es el libro de la vida. De toda la vida; material y espiritual, individual y social. Ella tiene su fuente en el amor gratuito de Dios. El Dios vivo -constantemente opuesto a dioses que "tienen boca y no hablan" (Salmo 115, 5)- es el Dios que libera a su pueblo. Liberar es dar vida.

El conocido pasaje de Lucas en que se enuncia el programa del Mesías esta centrado en la liberación:

El Espíritu del Sefior sobre mi, porque me ha ungido

para anunciar a los pobres la Buena Nueva, me ha enviado a proclamar la liberación a los cautivos

y la vista a los ciegos,

para dar la libertad a los oprimidos

y proclamar un anto de gracia del Sefíor $(4,18-19)$.

Las diferentes situaciones mencionadas (pobreza, cautividad, ceguera, opresión) aparecen como expresiones de la muerte; el anuncio de Jesús, ungido como el Mesías por la fuerza del Espíritu, la hará retroceder, introduciendo un principio de vida en la historia que debe llevarla a su plenitud. En este texto programático encontramos por consiguiente la disyuntiva muerte-vida, central en la revelación bíblica, frente a la cual el libro del Deuteronomio $(30,15)$ nos exige una opción radical.

Los pobres significan claramente en Lucas los desprovistos de lo necesario para vivir (cfr. Lc 6, 28; 7, 22; 14, 13-21; 16, 10.22; 18, 22; 19, 8; 21, 3). A ellos se les anuncia la liberación. La buena nueva para ellos se concreta en los tres enunciados que siguen: liberación a los cautivos, vista a los ciegos, libertad a los oprimidos. En todos esos casos la idea dominante es la liberación. Este es incluso el sentido de la expresión figurada "la vista a los ciegos" que traduce el texto hebreo de Isaías: "a los encadenados la abertura de los ojos." Se trata de una imagen que alude a la salida de la oscuridad de una prisión.

El reinado de Dios, reinado de vida, es el sentido último de la historia humana, pero su presencia se inicia desde ahora a partir de la atención de Jesús por los últimos de esa misma historia. De ello da testimonio el texto de Lucas: "Esta Escritura, que acaban de oír, se ha cumplido hoy" $(4,21)$. La palabra hoy es clave en la teología lucana (cfr. 2,$11 ; 3,22 ; 5,26)$; aquí con ella se quiere significar que la profecía de Isaías se realiza. Es el momento de la liberación de los pobres. La vida que El nos trae es, sin embargo, rechazada por muchos. Lucas nos relata que los auditores de su predicación quisieron despeñarle desde la altura de los 
cerros (cfr. 4, 28-30). El anuncio del evangelio de la liberación a los pobres no es una tarea fácil. Dar vida puede acarrear la muerte.

Algunas consideraciones sobre el libro de la Sabiduria son pertinentes aqui. El autor se propone, en condiciones difíciles y de crisis, reafirmar la esperanza de los creyentes, para ello relee los grandes libros que forman parte de la Biblia con el proposito de poner de relieve lo fundamental de su mensaje. Dicha relectura se hará en la perspectiva de la relación entre Dios y la vida.

Las nubes que se presentan en el horizonte no deben confundir a los creyentes. Estos deben saber pensar correctamente acerca de Dios; esa es la intención declarada de este escrito. Desde el inicio el autor afirma: "amen la justicia los que rigen la tierra; piensen correctamente del Señor y búsquenlo con corazón entero" (Sab 1, 1). Tener presente al Dios de la Biblia implica amar la justicia; estamos en la más genuina tradición profética. En efecto, Dios lleva ineludiblemente a querer lo que El ama; en consecuencia, la práctica de la justicia no se añade del exterior a nuestra amistad con Dios, forma desde dentro parte de nuestra relación con El. Esto debe ser buscado "con corazón entero;" Dios podría decir según una vieja y popular canción chilena: "corazones partidos yo no los quiero." Es una cuestión de integridad personal. No es posible "servir a Dios y a las riquezas," nos dirá Jesús en el evangelio de Mateo $(6,24)$. No se puede amar a Dios y practicar la injusticia, porque la explotación y el despojo del pobre, así como el consiguiente rechazo de Dios, significan escoger la muerte.

El libro de la Sabiduría trae al respecto una expresión que puede sorprender a primera vista: Dios no es el autor de la muerte. "No se procuren la muerte con su vida extraviada ni se acarreen la perdición con las obras de sus manos; Dios no hizo la muerte ni goza destruyendo a los vivientes" $(1,12-13)$. Ante la situación de muerte y persecución que sus lectores pueden enfrentar, el autor les recuerda que ella no viene de Dios; lo que significa que ella no debe ser vista por ellos como apoyada en su voluntad o como algo fatal. En nuestras manos está el transformar el momento que vivimos, es nuestra responsabilidad invertir el curso de los acontecimientos. No caben entonces resignaciones fáciles que quieren disimular, incluso con razones religiosas, nuestra cobardía.

Dios "todo lo cré para que subsistiera; las criaturas del mundo son saludables; no hay en ellas venenos de muerte ni el abismo impera en la tierra" (1, 14). La voluntad del Señor es vida. No existe en lo creado un ponzoñoso germen de muerte que un día se desarrollará necesariamente. Las criaturas han sido hechas para vivir en salud, la tierra existe para alimentar y acoger a los vivientes. Cuando nuestros hermanos campesinos de América Latina reclaman la tierta a la que tienen derecho (humano e histórico) no buscan inscribir sus nombres en los registros públicos de la nación, lo que exigen es ejercer su derecho a la vida. El abismo, el mundo de las tinieblas, no domina, no debe dominar la tierra y la vida de que ella es portadora.

La significación de la vida adquiere loda su dimensión con el tema de la tierra 
prometida Ella no es sólo el lugar donde los seres humanos encuentran el alimento cotidiano, ella es también el espacio de su libertad y dignidad personales. Esto forma parte también de la vida que tiene a Dios por autor. Desde una tierra en la que se deja de ser extranjeros y peregrinos, para convertirse en poseedores, en el ejercicio pleno de todos su derechos, los hombres y las mujeres podrán dirigir a Dios un culto "en esplritu y en verdad."

El libro de la Sabiduría después de esta rearimación de la vida, hace resaltar los sinuosos, pero fuertes lazos que existen entre los implos, es decir, los que no practican la justicia, y la muerte. "Porque la justicia es inmortal. Los impíos llarnan a la muerte a voces y con gestos, se consumen por ella, creyéndola su amiga; hacen pacto con ella, pues merecen ser su partido" (1,15-16). Declarar inmortal a la justicia es sostener que ella forma parte de la vida y que viene de Dios; sólo practicándola se puede pensar rectamente de Dios. Los impíos en cambio, son amigos de la muerte, la llaman a voz en cuello, hacen gestos para demostrarle su afecto; mueren por ella, si se puede hablar así. La siembran por doquier, violando los derechos de los demás.

No se trata de faltas ocasionales; el asunto es más grave: los que "no conocen los secretos de Dios" $(2,22)$ establecen un pacto con la muerte. Es una especie de contra-alianza. La alianza con Yahvé, el Dios de la vida, hace de los fimantes de ella defensores de la vida en la historia. Los que pactan con la muerte, constituyen un partido asesino y buscan que la muerte sea la última palabra de la historia humana Como en tantos otros libros brblicos, aquí también la vida y la muerte se oponen. No podemos evitar que hiera nuestros oídos la pregunta: ¿de qué partido somos? ¿De aquellos que participan activamente o por omisión en las violencias que hoy desgarran y trituran en particular a los pobres? $\_O$ de quienes también con "voces y gestos" y contra viento y marea dan un testimonio de vida, a veces al precio de su propia existencia?

Faltar contra Dios es haberse convertido, en un momento al menos, en partidario de la muerte, haber clanado por ella. Esa postura nos aleja de Dios. Pero allí está su misericordia siempre acogedora, dispuesta a que regresemos al carnino que conduce al reino. "A todos perdonas, porque son tuyos, Sefror, amigo de la vida" $(11,26)$. El amor de Dios es universal, nadie está excluido de su perdón, porque perdonar es dar vida. "Señor, amigo de la vida." Esta bella y profunda manera de designar a Dios resume el mensaje de la Sabiduría, así como la exigencia que presenta a todo creyente. Creer en Dios es ser, como El, amigo de la vida, en oposición a esos compafteros de ruta de la muerte que mencionábamos antes.

La liberación es voluntad de vida. La liberación se hace contra la opresión, la servidumbre y la muerte. En la raiz de toda injusticia social está el rompimiento de amistad con Dios y con los demás, el pecado. De ahí el carácter medular de la liberación del pecado que nos lleva a una nueva comunión con el Seffor y los otros. La liberación expresa una voluntad de vida; por eso, liberando, Dios se 
revela como un Dios liberador, como un Dios vivo, como el amigo de la vida. Ser cristiano es ser amigo del autor de la vida, de Jesús el Cristo.

\section{Hablar del Dios que libera}

En mi pais, el Perú, estamos marcados por el circulo infernal de diferentes violencias que se suscitan unas a otras, mordiéndose la cola cada vez con mayor velocidad Cada una de ellas presenta características propias; por eso, además de recordar la triple cara de esa situación, es importante tener presente sus particularidades. Sin duda la violencia más asesina - la que más niflos mata- es aquella que Medellín (y Puebla también) llama "institucionalizada," la pobreza cotidiana porque incluso es aceptada como "orden legal." A ella se aflade la injustificable violencia terrorista que sigue lienándonos de horror y de repulsa. Por su parte la violencia represiva con que se pretende rechazar el terrorismo es inaceptable y especialmente escandalosa por que pretende defender los valores humanos de nuestra sociedad. No es posible resignarse a tal estado de cosas. No cabe tampoco el desinterés por el asunto con el pretexto que aún no hemos sido tocados directamente por él. De otro lado, la actitud de venganza personal, o por intermediario, no hara sino echar lefta al fuego. Un fuego que amenaza dejar en cenizas a nuestro país.

La pregunta, en este contexto, es ¿cómo ser amigos de la vida en el Perú de hoy? Una de las grandes tareas de los cristianos, de la Iglesia entera, es defender los derechos humanos que las violencias mencionadas pisotean diariamente. $Y$ hemos aprendido en este tiempo, en América Latina y en el Perú, que esa defensa significa enfrentar poderosos intereses, sobre todo cuando ella se hace desde los más débiles de la sociedad, desde los pobres y oprimidos. Pero el mandato que tenemos como comunidad cristiana, como Iglesia, no es sobrevivir, sino servir. Hoy, en América Latina, la Iglesia se está jugando el sentido de su identidad en tanto comunidad de discípulos de Aquel que vino para que tuviéramos "la vida y la vida en abundancia" (Juan 10,10). De su testimonio y no de vacías formalidades depende la afirnación de su identidad.

La disyuntiva es clara. $O$ nos desinteresamos de lo que sucede so capa de que no es nuestra responsabilidad directh, nos limitamos a hacer invocaciones líricas a la unión de todos, nos replegamos por temor y pretendemos estar por encima de las oposiciones que hoy se dan en la sociedad latinoamericana, y en ese caso habremos llamado a la muerte convirtiéndonos en su partido, como dice la Sabiduria, en el momento mismo en que pretendiamos no optar. $O$ sabemos estar presentes sin esquivas neutralidades, alli donde las fuerzas contrarias al reino de amor y justicia violan agresiva y diariannente los derechos humanos más elementales, y entonces estaremos comenzando a comportarnos como amigos de la vida. El tema de la vida y la muerte resulta decisivo en la revelación bíblica sobre Dios (ffr. Salmo 104, 29-30).

Solo guardando silencio y siendo solidarios con el sufrimiento de los pobres 
se podra hablar desde su esperanza sobre el Dios que libera. Esperanza que anima creativa y tenazmente la construcción de un mundo justo, humano y fraterno. Los esfuerzos sociales y políticos, as/ como las vivencias religiosas de los pobres, constituyen las reservas más sanas de nuestro continente. La pobreza es carencia, pero también fuente de solidaridad; es muerte, pero igualmente sensibilidad al don de la vida. A partir de allí nace entre nosotros un lenguaje contemplativo que reconoce que todo viene del amor gratuito del Padre, y un lenguaje profético que nos recuerda su exigencia de justicia Ambos se entrelazan para hablarnos del Dios de Jesús.

Pocos lo han expresado mejor que ese gran testigo del evangelio de nuestros días que es Desmond Tutu. "La teologia de la liberación - dice el obispo desde el abismo de dolor y abandono en que se encuentra su pueblo- más que cualquier otro tipo de teologia, surge del crisol de la angustia y los sufrimientos humanos. Surge porque el pueblo grita: "Seflor, ¿hasta cuándo? Oh Dios, ¿pero por qué?" (...) Toda teología de la liberación proviene del esfuerzo por dar sentido al sufrimiento humano cuando aquellos que sufren son víctimas de una opresión y explotación organizada, cuando son mutilados y tratados como seres inferiores a lo que son: personas humanas, creadas a imagen del Dios trino, redimidas por un solo Salvador Jesucristo y santificadas por el Espíritu Santo. Este es el origen de loda teología de la liberación y, por tanto, de toda teología negra, que es teología de la liberación de Africa."

La frase evangélica "los últimos serán los primeros" vale para el acceso al reino de Dios, por consiguiente rige para la teología que no es sino un intento de hablar acerca del Dios del reino. Un discurso sobre la fe que no tenga en cuenta la amplia y honda cuestión del sufrimiento de los pueblos que se tutean con la muerte temprana e injusta se niega él mismo como lenguaje sobre el Dios que "del más chiquito tiene la memoria muy viva," como decía Bartolomé de Las Casas.

Con todos nuestros límites y deficiencias, conscientes de lo parcial e insuficiente de nuestros intentos de respuesta a cuestiones que nos abruman, en el marco de la teologia de la liberación tratamos - con angustia y esperanza a la vez- de evitar que los pobres nos lancen a la cara el reproche de Job a sus amigos: "ustedes son unos consoladores inoportunos" $(16,2)$.

\section{Noles}

1. Erte a un ponencia enviede al seminario "Dioe hoy," dirigido por Olegario Gonźlez de Cariedal, celebrado en El Escorial del 4 al 18 de julio, dentro de la Universidad de Verano de la Comphtutense de Madrid

2. Cinded periane, ayo nambre signifiea en quechus "rincon de los muertos." 